\title{
Origin of the Drastic Current Decay During Potentiostatic Alkaline Methanol Oxidation Electronic Supplementary Information
}

Theresa Haisch, ${ }^{\dagger \neq}$ Fabian Kubannek, Dejun Chen, "YuYe J. Tong, ${ }^{\mp}$ and Ulrike Krewer ${ }^{*, \ddagger}, \S$

$\dagger$ †ECHEMA Research Institute, 60486 Frankfurt am Main, Germany

$\ddagger$ Institute of Energy and Process Systems Engineering, TU Braunschweig, 38106

Braunschweig, Germany

9Department of Chemistry, Georgetown University, Washington D.C. 20007, USA

§Institute for Applied Materials, Karlsruhe Institute of Technology, 76131 Karlsruhe,

Germany

E-mail: ulrike.krewer@kit.edu

Phone: +49 721 608-47491

This PDF file includes:

Band shift FTIR

Figs. S1 to S7

SI References 
Band shift FTIR: The Stark effect describes the splitting of spectral lines in an electrical field. The presence of an electrical dipole moment is the prerequisite that a molecule can be subject to the Stark effect; this is the case with CO. In the course of the CV measurement, the increase in the applied electric field at the interface leads to an intensification of the Stark effect. ${ }^{1}$ In addition to the Stark effect, there is another influence. With increasing CO coverage, the frequency shifts to higher values due to coupling effects, which intensify the competition for the back binding of the electrons. ${ }^{2}$

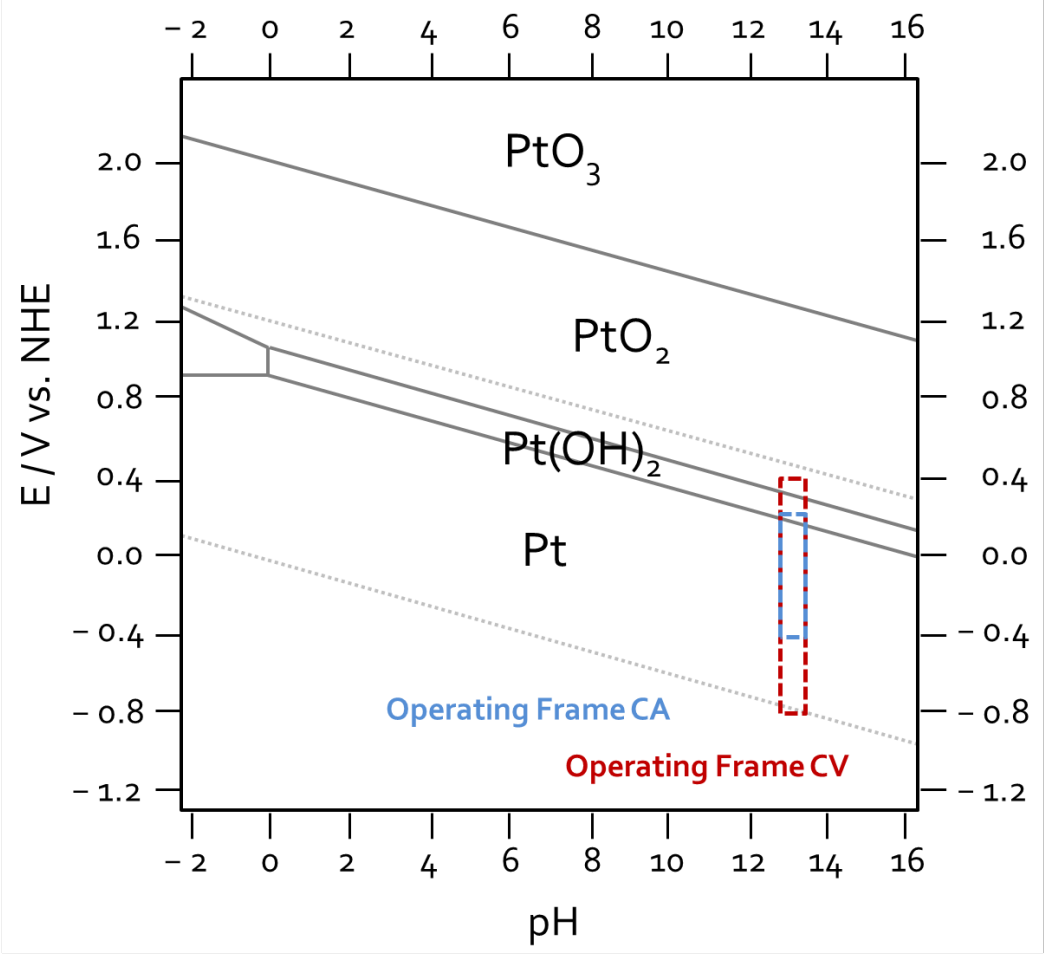

Figure S1: Potential- $\mathrm{pH}$ (Pourbaix) diagram of platinum in water at $25^{\circ} \mathrm{C}$. The dotted lines represents the OCP of oxygen (upper line) and hydrogen (lower line) evolution. The open circuit potential $(\mathrm{OCP})$ value of the methanol electrooxidation is close to that of hydrogen evolution (0.02 V vs. RHE). Redrawn from. ${ }^{3}$ 


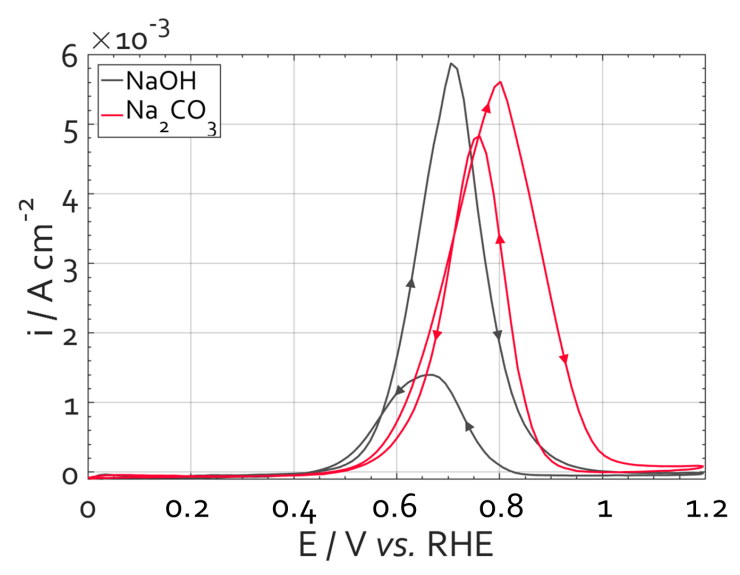

(a)

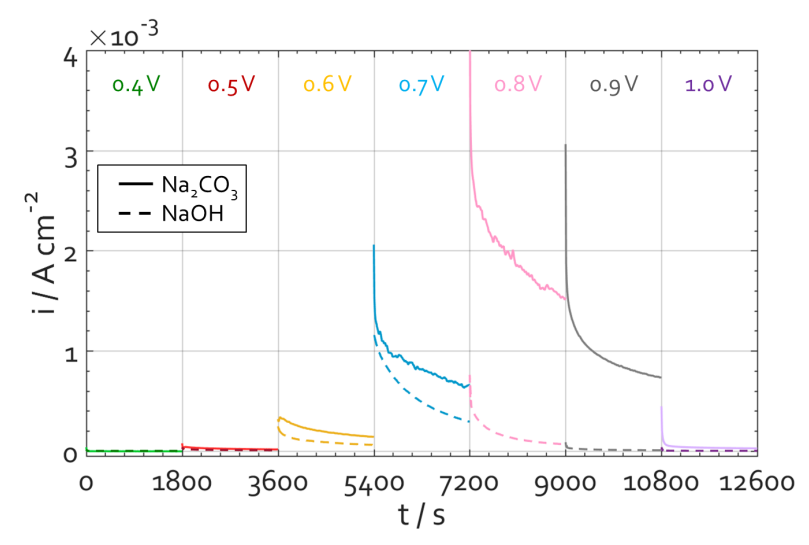

(b)

Figure S2: a) Experimental cyclic voltammograms of a $0.5 \mathrm{M}$ alkaline methanol solution (0.5 $\mathrm{M} \mathrm{NaOH}$ or $0.5 \mathrm{M} \mathrm{Na}_{2} \mathrm{CO}_{3}$ ) on a smooth platinum RDE at $100 \mathrm{rpm}$. Scan rate $20 \mathrm{mV} \mathrm{s}^{-1}$. b) Current time curves of the same solutions as in a) in response to a series of potential steps from $0.4 \mathrm{~V}$ to $1 \mathrm{~V}$.

Fig. S2a: The $\mathrm{CV}$ in $\mathrm{Na}_{2} \mathrm{CO}_{3}$ is shifted towards higher potentials by approximately $100 \mathrm{mV}$. This potential shift is not the reason for the decline in current density during CA because the current density declines not only at $0.77 \mathrm{~V}$, but also at 0.87 and $0.97 \mathrm{~V}$. Furthermore the concentration of $\mathrm{CO}_{2}$ produced by the MOR is far lower than that of an electrolyte containing only $\mathrm{Na}_{2} \mathrm{CO}_{3}$.

Fig. S2b: The current drop can be observed for both solutions for all applied potentials. Currents in the carbonate electrolyte are equally high or higher than in the hydroxide electrolyte. Thus, carbonate formation does not appear to block methanol oxidation. 


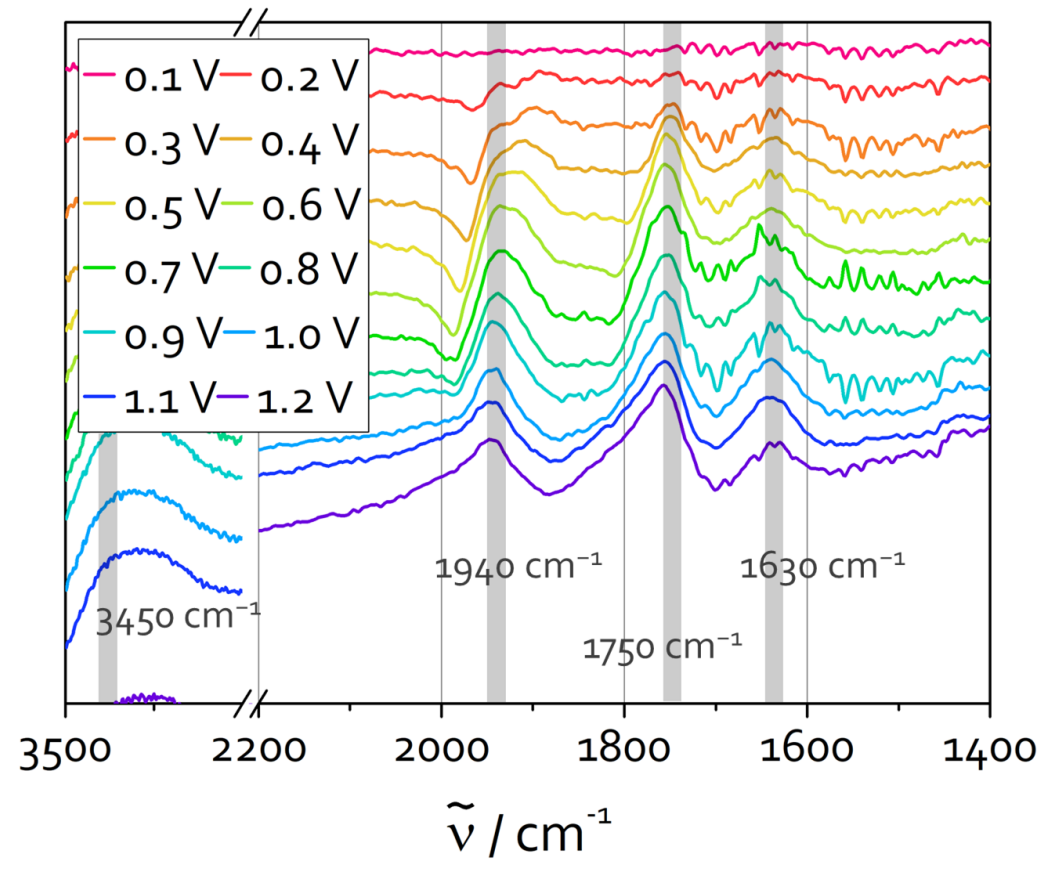

Figure S3: In situ FTIR spectra of a $0.1 \mathrm{M} \mathrm{NaOH}+0.1 \mathrm{M} \mathrm{C}^{13} \mathrm{H}_{3} \mathrm{OH}$ solution on a thin platinum film catalyst during potentiodynamic measurement with a scan rate of $10 \mathrm{mV} \mathrm{s}^{-1}$. Displayed potentials are vs. RHE. The assignment of the band to the adsorbed species can be found in Table 1 of the main text of the paper.

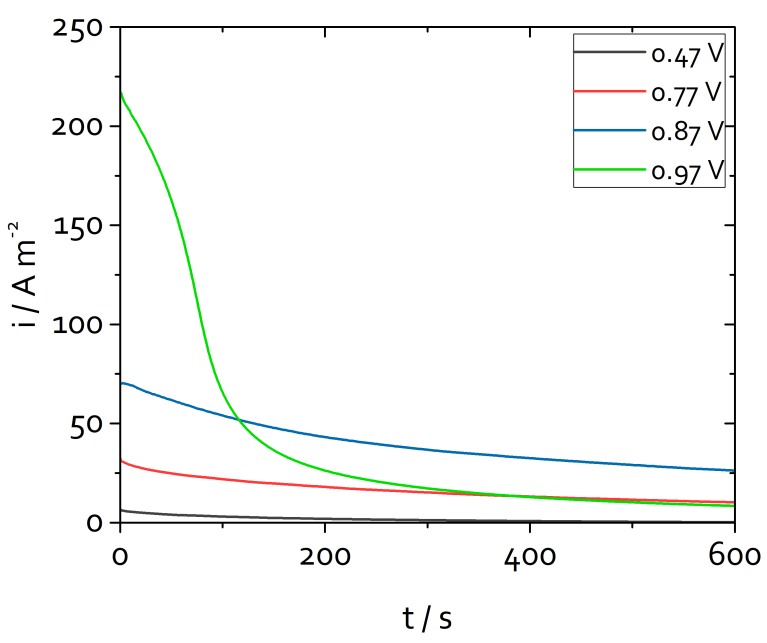

(a)

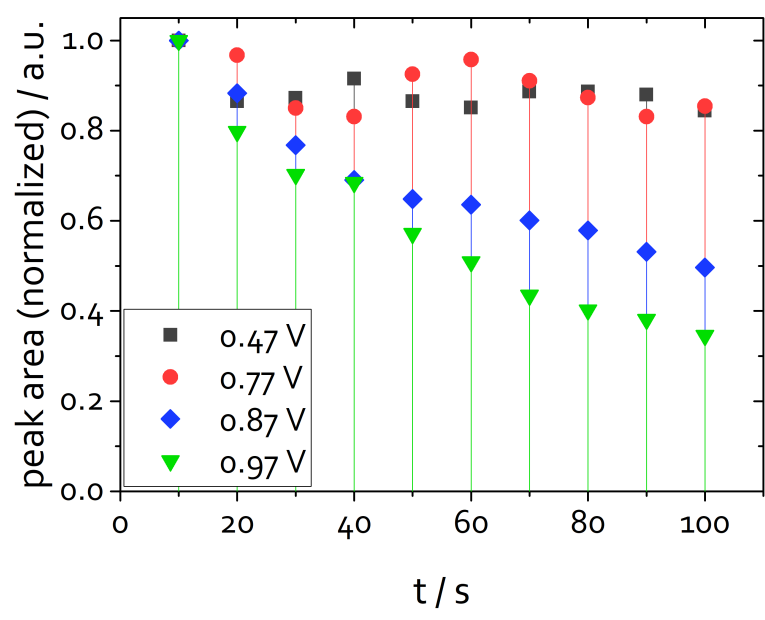

(b)

Figure S4: a) Current-time curves of a $0.1 \mathrm{M} \mathrm{NaOH}+0.1 \mathrm{M} \mathrm{MeOH}$ solution at potentials of $0.47,0.77,0.87$ and $0.97 \mathrm{~V}$ vs. RHE on a smooth platinum RDE at $100 \mathrm{rpm}$. b) Corresponding integrated in-situ SEIRAS peak areas for CO (normalized). 


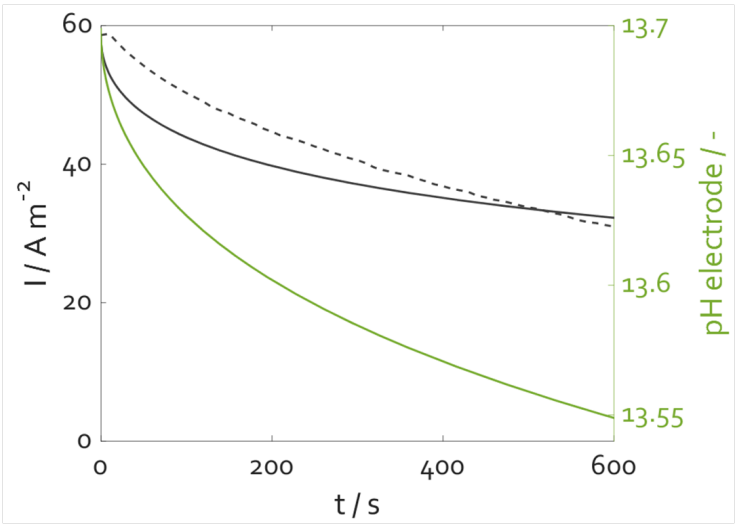

Figure S5: Left axis: Simulated (solid) and experimental (dashed) current-time curves of a a) $0.5 \mathrm{M} \mathrm{NaOH}+0.5 \mathrm{M} \mathrm{MeOH}$ solution on a Pt-RDE (100 rpm) at $0.7 \mathrm{~V}$ vs. RHE. Right axis: Simulated $\mathrm{pH}$ value with the same parameters.

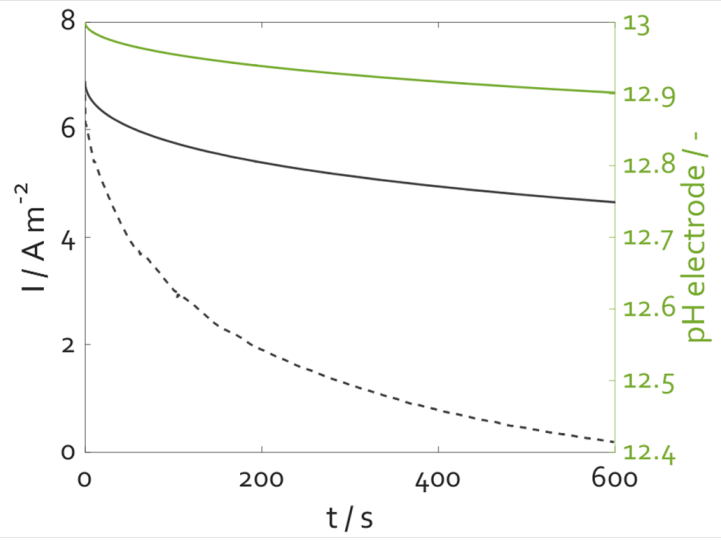

(a)

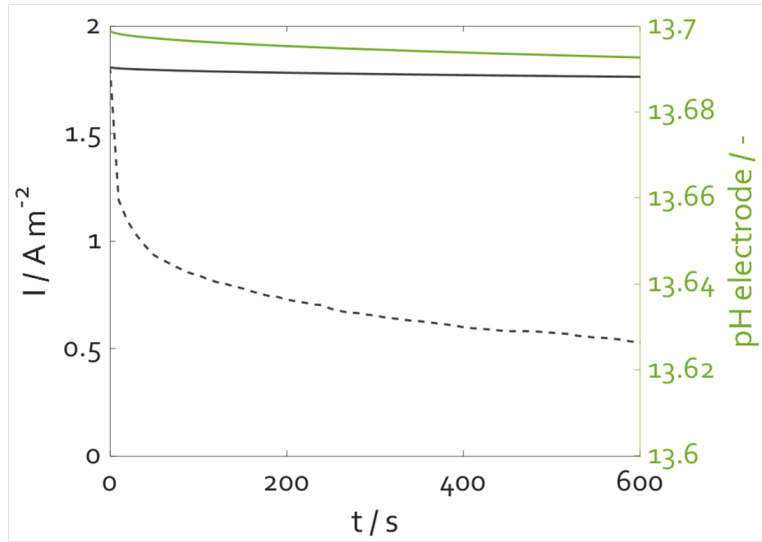

(b)

Figure S6: Left axis: Simulated (solid) and experimental (dashed) current-time curves on a Pt-RDE (100 rpm) of a a) $0.1 \mathrm{M} \mathrm{NaOH}+0.1 \mathrm{M} \mathrm{MeOH}$ solution at $0.47 \mathrm{~V}$ vs. RHE and b) $0.5 \mathrm{M} \mathrm{NaOH}+0.5 \mathrm{MeOH}$ at $0.50 \mathrm{~V}$ vs. RHE. Right axis: Simulated $\mathrm{pH}$ value with the same parameters.

Fig. S5: Figure S5 shows the simulated and experimental curves of a current-time measurement for a $0.5 \mathrm{M} \mathrm{NaOH}+0.5 \mathrm{M} \mathrm{MeOH}$ solution. It can be seen that for both curves the current density drop is of the same order of magnitude. A comparison of the pH shift of the curves recorded at $0.1 \mathrm{M}$ (Fig. 5) and $0.5 \mathrm{M}$ shows that the shift is slightly higher at the lower concentration. However, this is also to be expected, since a lower $\mathrm{NaOH}$ concentration leads to a lower $\mathrm{OH}$ coverage on the catalyst surface and therefore a local lack of hydroxide ions is more likely to occur. 
Fig. S6: Figure S6 shows the dependence of current decay for a lower potential for experiment and simulation. In both cases experiment and simulation show a current decay, whereas it is significantly smaller for simulation, i.e. only part of the decay is explained by the simple one-step model. This is explained in the following. The alkaline methanol oxidation has a very complex reaction mechanism which among others strongly depends on the reaction mechanism. The model is based only on the simple reaction of methanol to carbonate. No further kinetic considerations, e.g. for intermediates are made. For this reason, a suitable correspondence between simulation and experiment is only found in the potential range of the associated CV near the peak maximum. After the peak maximum, the platinum oxide formation plays a decisive role with regard to the active catalyst surface, which is considered constant in the model. ${ }^{4}$ At low potentials, the catalyst surface is covered by a large amount of CO and hardly any methanol oxidation takes place. At these potentials, thus other effects additionally contribute to the current decline's main part that are not covered by the simple 1-step reaction-diffusion model. We attribute this to the in total very low currents at that potential range and the dominance of strongly adsorbed intermediates, which are not covered by our very simple model but whose kinetics may also be sensitive to $\mathrm{pH}$. This argumentation is supported by the finding that we have much larger $\mathrm{pH}$ change for the low concentration simulation and for the experiment compared to high concentrated solution where the small current causes no change in $\mathrm{pH}$.

Fig. S7: The rotation rate is another variable we are using in the model. Based on the Levich relation, increasing the rotation leads to an increase in the current density. However, our experiments show the opposite dependence which is also in accordance with literature: The initial point and the full experimental curve is lower for $400 \mathrm{rpm}$ compared to 100 rpm (Fig. S7). ${ }^{5}$ Analyzes of bulk samples have shown that the amount of formaldehyde (an intermediate of the alkaline MOR) in the bulk solution increases with an increasing rotation rate leading to a loss of intermediates for further reaction steps. For the simulation the initial point is fixed to the experiment and similarly to experiment the $400 \mathrm{rpm}$ curve is therefore 


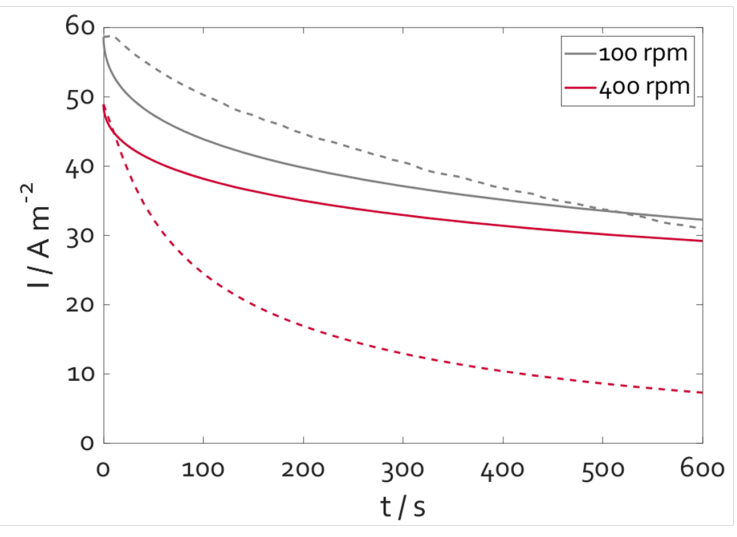

(a)

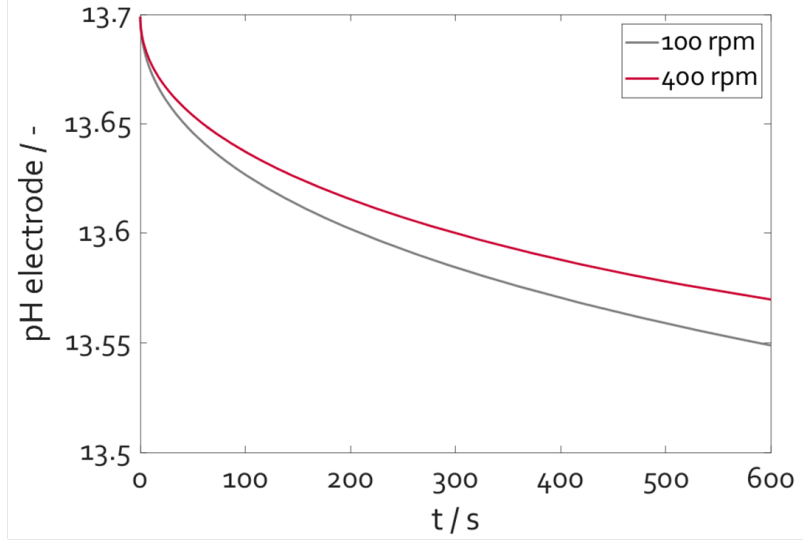

(b)

Figure S7: a) Simulated (solid) and experimental (dashed) current-time curves of a $0.5 \mathrm{M}$ $\mathrm{NaOH}+0.5 \mathrm{M} \mathrm{MeOH}$ solution on a Pt-RDE at $0.70 \mathrm{~V}$ vs. RHE with different rotation rates (100 rpm and $400 \mathrm{rpm})$. b) Simulated $\mathrm{pH}$ value with the same parameters.

below the 100 rpm curve. This holds for the full progression of curve and corresponds to the experiments. However the model can not explain the higher removal of intermediates at higher rotation rates as it does not contain the intermediates desorption. In contrary, the higher transport is visible by a smaller $\mathrm{pH}$ change in the model. These results are also the reason why we focus our analysis to a very low rotation rate $(100 \mathrm{rpm})$ for the model and experiments in the paper in order to minimize the effect of intermediate transport.

\section{References}

(1) Chen, D.-J.; Hofstead-Duffy, A. M.; Park, I.-S.; Atienza, D. O.; Susut, C.; Sun, S.G.; Tong, Y. J. Identification of the Most Active Sites and Surface Water Species: A Comparative Study of CO and Methanol Oxidation Reactions on Core- Shell M@ Pt $(\mathrm{M}=\mathrm{Ru}, \mathrm{Au})$ Nanoparticles by in Situ IR Spectroscopy. J. Phys. Chem. C 2011, 115, $8735-8743$.

(2) Lane, G.; Miller, J.; Modica, F.; Barr, M. Infrared spectroscopy of adsorbed carbon monoxide on platinum/nonacidic zeolite catalysts. Journal of Catalysis 1993, 141, 465477. 
(3) Pourbaix, M.; van Muylder, J.; de Zoubov, N. Electrochemical properties of the platinum metals. Platin. Met. Rev. 1959, 3, 47-53.

(4) Haisch, T.; Kubannek, F.; Nikitina, L.; Nikitin, I.; Pott, S.; Clees, T.; Krewer, U. The origin of the hysteresis in cyclic voltammetric response of alkaline methanol electrooxidation. Phys. Chem. Chem. Phys. 2020, 22, 16648-16654.

(5) Haisch, T.; Kubannek, F.; Haisch, C.; Bahnemann, D. W.; Krewer, U. Quantification of formaldehyde production during alkaline methanol electrooxidation. Electrochem. Commun. 2019, 102, 57-62. 